the circumstances and prevent sodium retention. (3) The failing kidney can, when required, still conserve sodium.

Fig. D also shows a hypertensive uraemic patient on the rice diet. His blood urea was $90 \mathrm{mg}$. per $100 \mathrm{ml}$. It will be seen that he was still able to reduce his sodium excretion to negligible amounts, though it took him longer than the normal person to do so. His tubules were finally reabsorbing about $99.8 \%$ of the sodium reaching them.

In the case of potassium I showed (Platt, 1950) that in renal failure not only do the tubules reject a greater fraction of the load delivered to them by filtration, but in severe cases the rate of excretion may actually exceed the rate of filtration of potassium ; in other words, the potassium clearance may exceed the creatinine or inulin clearance. This can only mean that a mechanism exists for the active tubular excretion of potassium. Leaf and Camara (1949) found the same phenomenon in chronic renal failure, and McCance and Widdowson (1937), in a case of renal failure due to alkalosis, reported a potassium clearance temporarily greater than that of inulin. Berliner and Kennedy (1948) have shown that tubular excretion of potassium may be induced in normal dogs under special circumstances. We have since found the same phenomenon in experimental renal failure in the rat. One of our rats, whose blood urea rose to $636 \mathrm{mg}$. per $100 \mathrm{ml}$, had a potassium clearance more than twice that of his creatinine clearance.

This demonstration of the active tubular secretion of potassium is another indication that the remaining remnant of renal tissue, both in experimental and in human renal failure, can perform extraordinary feats. The renal tubules behave not as a machine failing and giving out but as a mechanism pushed to the limit of its capacity. It is only in the study of human disease that such adaptations are revealed; and having been revealed in the extremes of disease, they may disclose a normal mechanism hitherto unsuspected.

We may briefly summarize this section by saying that excretion of sodium and potassium is efficiently maintained in renal failure, first by the simple device of the remaining tubules reabsorbing a smaller proportion of these substances, and, secondly, in the case of potassium, by a process of active tubular excretion.

\section{Phosphate and Calcium}

The anion phosphate does not behave like the cations sodium and potassium in renal disease, for it is retained by the kidney and may reach high levels in the blood. As with urea, the high plasma level facilitates the excretion of phosphate, and the phosphate clearance approaches but does not exceed that of inulin or creatinine (Platt, 1950).

In calcium metabolism we have an excellent example of a train of adaptations which can be set in motion by renal failure. The usual tendency is for the plasma calcium to fall, and several factors are concerned in this. One is the high plasma phosphate level which, in accordance with the usual reciprocal relationship between calcium and phosphate, will tend to depress the calcium level. A high plasma phosphate probably also interferes with calcium and phosphate absorption from the intestines. A third factor probably contributing to calcium depletion is acidosis, if calcium is used as a base with which to excrete acid radicals.

There is need for further work in assessing the relative importance of the several factors involved.

Whatever be the cause or causes of the low plasma calcium, it appears to act as a stimulus to the parathyroids
(Stoerk and Carnes, 1945 ; Albright and Reifenstein, 1948), and these glands are found to be hyperplastic in renal failure (Pappenheimer and Wilens, 1935). The excess of parathyroid hormone tends to restore the plasma calcium towards normal by mobilizing calcium from bone (Follis, 1950 ; Milne, 1951). This adaptation, while preventing tetany and other ill effects - of calcium deficiency, has a side-effect in cases of renal failure of long duration, especially in young persons, in causing the bony changes of hyperparathyroidism to appear, which Albright and Reifenstein have called "renal osteitis fibrosa" (Fig. E). It should be

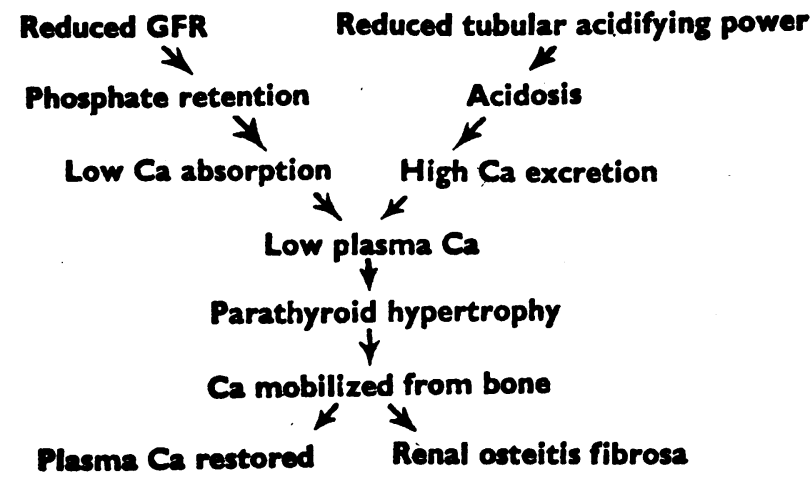

F1G. E.-Scheme showing the effect of renal failure on calcium metabolism (modified from Albright and Reifenstein, 1948).

mentioned that the older term " renal rickets" is not entirely a misnomer, since Follis (1950), by careful histological examination, has shown that changes typical of rickets or osteomalacia may also be found. Thus there would seem to be a factor interfering with the deposition of calcium and phosphorus in bone in addition to the parathyroid action favouring bone resorption. In all probability the acidosis itself both contributes to the mobilization of calcium from bone and interferes with its deposition. The bony changes can sometimes be reversed by a combination of low phosphorus diet, alkali therapy, and calciferol.

It is extraordinary how promptly parathyroid hypertrophy occurs, at any rate in the rat. Our rats' parathyroids showed clear evidence of hyperplasia with mitoses within 14 days of removal of their renal tissue (Platt, Roscoe, and Smith, 1952).

It would be impossible in the time at my disposal, and it would in any case be tedious, to attempt a complete survey! of what is known of functional adaptation in renal disease. For instance, the kidney's defence against acid accumulation in the body is put to a severe test, and yet clinical and biochemical evidence of acidosis is generally lacking until the final stage of disease. It is known that the failing kidney cannot produce a highly acid urine, nor can it produce ammonium ion in adequate amount to neutralize the anions it must excrete; but these aspects of our subject and the excretion of bicarbonate in renal failure are as yet inadequately investigated, and I have no new observations to offer.

\section{The Excretion of Water}

The rate of water excretion seems to be determined in normal individuals by two main factors. The first is the solute load: we have already seen that there is a certain minimum rate of urine flow which is necessary for the excretion of dissolved substances, and when solutes are present in excess, as in the clinical state of diabetes mellitus, the amount of water excreted increases very greatly. This type of polyuria is known as osmotic diuresis because the increased osmotic pressure of the tubular fiuid prevents the reabsorption of water which is believed to take place in the proximal tubule. Even under normal circumstances the amount of water we excrete is largely determined by the 
solute load and especially by the varying need to excrete electrolytes (Stanbury and Thomson, 1951), since the rate of excretion of urea is much more constant.

In renal failure, as we have already seen, the rate of excretion of all urinary constituents such as urea, sodium, potassium, phosphate, and chloride remains remarkably normal, and so the rate of water excretion must remain at least normal also, though actually it increases because of the inability of the failing kidney to produce a concentrated urine. This inability to concentrate we have discussed in the first lecture, where it was pointed out that the excretion of a normal quantity of urinary solutes by a fragment of functioning kidney clearly implies that each nephron is doing far more than a normal share of work. If only a tenth of the normal number of nephrons remains, each is excreting 10 times its normal quota of solutes and so must behave as if an osmotic diuresis were constantly in operation. Far less water is therefore reabsorbed by the tubules in renal failure than in the normal kidney, and this statement can be checked by a very simple calculation. If a normal person has a urine flow of $1 \mathrm{ml}$. per minute and a glomerular filtration rate of $100 \mathrm{ml}$. per minute he is reabsorbing $99 \%$ of his filtered water ; but if a renal failure patient has the same urinary output and a glomerular filtration rate of only $10 \mathrm{ml}$. per minute he is obviously reabsorbing only $90 \%$ of his filtered water, and the rate of urine flow per tubule is increased tenfold. Because of the osmotic diuresis the rate of flow will actually be even greater. This is probably related to the tubular dilatation, which is, as we have seen, such an obvious structural feature of the failing kidney. The polyuria of renal failure is of course accompanied by an increased water intake and by conscious thirst in severe cases.

The second determinant of water excretion comes into operation when water itself is present in excess. This is mediated, as Verney (1947) has shown, by the osmoreceptors, which inhibit the secretion of pituitary antidiuretic hormone.* There are thus two types of diuresis: osmotic diuresis in which the urine approaches the concentration or osmolarity of the plasma ; and water diuresis, best seen after the ingestion of a litre or more of water, in which the urine becomes extremely hypotonic, approaching the osmolarity of distilled water (Frey and Frey, 1950).

According to Wolf, the Sioux Indians used water diuresis as an alarm clock, adjusting the dose of water to be drunk before retiring according to the time they wished to go out on the war trail in the morning. I suppose that they worked it out empirically, unless they were aware that the amount of the diuresis is approximately proportional to the logarithm of the time (Wolf, 1950).

It has long been known that the failing kidney cannot produce an efficient water diuresis, and this, of course, is the basis of the Volhard dilution test.

\section{Water Diuresis}

Fig. $F$ shows the effect that drinking $1,100 \mathrm{ml}$. of water had on myself and on a patient with severe renal failure whom Dr. Roscoe and I investigated and whose blood urea at the time of the test was $290 \mathrm{mg}$. per $100 \mathrm{ml}$.

In the normal subject the water output rose sharply to $16 \mathrm{ml}$. per minute, a highly efficient but socially inconvenient response, whereas the patient reached a urine flow of only about $4 \mathrm{ml}$. per minute. Thus the speed of getting rid of a water load of this magnitude is much reduced in renal failure. The same thing occurs in rats deprived of renal tissue (Platt, Roscoe, and Smith, 1952). The graph also shows what again is well known, that water diuresis is not brought about by increasing the rate of filtration at the glomerulus, but (on current theories) by reducing the amount

*It should be noted in passing that the adrenal cortex is in some way necessary to water diuresis, since patients with adrenal insufficiency cannot excrete water efficiently; but this faculty is restored by the administration of cortisone (Oleesky and restored by tanbury, 1951).
Ste

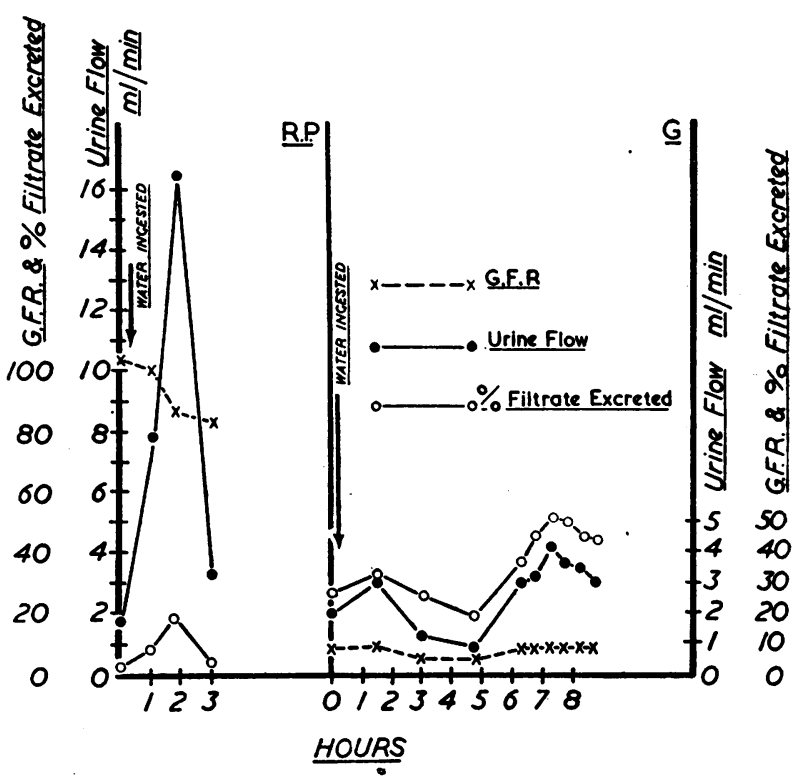

FIo. F.-Water diuresis in a normal subject and in renal failure (see text).

of water reabsorbed in the tubules. It shows further that in spite of the ingestion of this large amount of water about $80 \%$ of the filtered water is still being reabsorbed in the normal kidney, thus confirming Homer Smith's (1937) assertion that the reabsorption of $80 \%$ or more of the filtered water is obligatory. But in the case of the patient, the filtration rate (measured by both inulin and creatinine clearance) was only about $8 \mathrm{ml}$. per minute, and at the height of his diuresis he reached a urine volume of $4.16 \mathrm{ml}$. per minute, or about $50 \%$ of his filtered water, thus upsetting normal conceptions of water reabsorption rather badly: another example of the value of studying physiological mechanisms when they are contending with the stress of disease. Some of this effect was due to osmotic diuresis, but much was due to water ingestion, because the patient's urine at the height of the diuresis was only about half isotonic with regard to sodium, containing $70 \mathrm{mEq}$ of sodium per litre.

Now, in order to produce a hypotonic urine in respect of sodium (or some other solute), obviously a hypertonic solution must be reabsorbed by the tubules. Given the filtration rate and the plasma and urinary concentrations of sodium, the sodium content of the reabsorbed fluid can be calculated, the calculation being:

$$
\frac{\% \text { reabsorption of sodium }}{\% \text { reabsorption of water }} \times \text { plasma sodium }
$$

Because of the very low glomerular filtration rate, it is much more difficult for the patient to secrete a hypotonic urine than for the normal subject, and a much more hypertonic fluid has to be reabsorbed by the tubules. Calculation shows that, in order to produce the hypotonic urine which was actually found in this case, a strongly hypertonic solution ( $216 \mathrm{mEq} \mathrm{Na}$ per litre) must have been reabsorbed all the way along the renal tubule, and that the renal tubular function would have had to be much more efficient in this respect than has ever been demonstrated in a normal subject.

While this is not impossible, we must remember that the whole basis of the calculation is the assumption that water diuresis is purely a question of filtration and reabsorption; and that assumption, which is currently accepted by renal physiologists, I would like seriously to question. If we postulate instead a mechanism for the tubular secretion of water, or more probably of a hypotonic fluid, the observed facts can be explained much more simply, and, I think, in a manner more consistent with what we know of physio- 
logical processes. Such a theory would have three advantages as an explanation for the observed facts. First, it would avoid the necessity for assuming that the renal failure patient is capable of reabsorbing a much more highly concentrated solution than the normal, and, although it assumes as an alternative that some part of the renal tubule can secrete a very hypotonic fluid, it is assumed that this is a function also present in the normal kidney. Secondly, it would avoid the assumption that a renal failure patient reabsorbs only $50 \%$ of his filtered water whereas in extreme conditions of diabetes insipidus plus osmotic diuresis the normal kidney still reabsorbs about $80 \%$ (Brodsky and Rapoport, 1951). Thirdly, assuming that the increased urine volume during water diuresis was due to tubular secretion of water, in our experiment we could conclude that the normal subject can secrete about $15 \mathrm{ml}$. of water per minute, whereas the renal failure patient secretes only about $2 \mathrm{ml}$. per minute-a fraction consistent with the amount of functioning renal tissue which he probably possessed.

You might well ask why, if this is the case, the kidney should perform its functions in such diverse ways; but if tubular secretion of potassium occurs, why not water secretion? And let me remind you that although the kidney is a highly efficient organ the evidence of comparative anatomy, of embryology, and of evolution suggests that it has developed in what would seem to be a somewhat haphazard manner. The kidneys of certain marine teleosts, although they have no glomeruli at all, can yet secrete a hypotonic urine (Marshall, 1930), and it seems to me not beyond reason that this function has been passed on to the mammalian kidney.

Since we elaborated this theory, Brodsky and Rapoport (1951) have also concluded from their studies on osmotic diuresis in subjects with diabetes insipidus that tubular secretion of water is more consistent with the facts and less extravagant in renal osmotic work than water excretion solely by filtration and reabsorption. Dr. Roscoe is at present making further studies of this question, but allows me to say that she has now made the very striking observation that in two cases of terminal renal failure she has found a serum creatinine concentration considerably higher than that of the urine. Since tubular reabsorption of water can only concentrate the urine and not dilute it, this would be proof of water secretion, if we were quite sure that creatinine clearance was a true measure of the glomerular filtration rate. Unfortunately we cannot be certain of this, and there are known fallacies in the estimation of serum creatinine (Lauson, 1951). Despite these uncertainties this would seem to be very strong evidence in favour of water secretion. If it does occur we do not, of course, know whether it is a function of the proximal or the distal tubule, or perhaps of that evasive structure, the loop of Henle.

A few practical inferences can be drawn from our consideration of the excretion of solutes and water in renal failure.

The kidney is performing a minimum amount of work when it produces a urine the composition of which differs as little as possible from that of the plasma. The salt content of urine is usually less than that of plasma, whereas the urea content is normally much greater. Therefore we must restrict protein intake to reduce urea excretion, but must give an adequate, in fact a liberal, ration of salt. The failing kidney needs a generous supply of water for its excretion of solutes, but has difficulty in getting rid of water in excess. In determining water intake the instinctive demands of the patient, regulated as they are by an extremely efficient thirst mechanism, are usually the most accurate guide.

\section{Hypertension in Renal Failure}

Before discussing my final subject, which is renal anaemia, I will include a few words on the relation of hypertension to renal disease. I cannot consider it here in detail, and there is so much unsettled controversy that it is a subject which must either be dismissed very briefly or be discussed at great length.
The fact that chronic renal disease is very often (though not constantly) associated with hypertension, and the fact that the glomerulus is primarily dependent upon the blood pressure for its function of filtration, suggest that hypertension is an adaptation called into play to raise the glomerular pressure. Goldblatt's (1934) classical experiments seemed to confirm this by showing that reduction in renal blood flow had hypertension as its inevitable sequel. Further work, however, has led to many complications and little clarification. The concept of a simple relationship between blood pressure and renal blood flow is difficult to maintain in view of the experiments of Grollman, Turner, and McLean (1951), who showed that dogs kept alive by peritoneal irrigation after total nephrectomy developed severe hypertension.

The subject has not been much illuminated - by the continual confusion in the work of some authors (e.g. Goldring and Chasis, 1944 ; Homer Smith, 1951) between essential hypertension, the origin of which is still unknown, and renal hypertension, which would seem to be clearly related to pre-existing unilateral or bilateral disease of the kidneys. One thing seems certain from the work of Wilson and Byrom (1941) and Byrom and Dodson (1948)-namely, that whatever the origin of the hypertension, even if it be at first adaptive and beneficial to survival, it can reach a stage when a vicious circle sets in and further elevation of blood pressure leads to arteriolar necrosis with serious and rapid deterioration in renal function. This is a syndrome often encountered when severe hypertension and renal disease coexist.

\section{The Anaemia of Renal Failure}

My last section is devoted to the consideration of a condition which is invariably present in renal failure-namely, anaemia. Its origin has long been a mystery, and, though I shall bring forward a new hypothesis concerning its causation, I cannot claim that the mystery is yet solved.

First of all I would like to set out some of the known facts, which are as follows:

1. All cases of renal failure with prolonged nitrogen retention, whatever the cause, are accompanied by anaemia. The anaemia is independent of the presence or absence of hypertension.

2. The anaemia is normochromic in type. In my department, 84 observations on 49 patients showed a colour index between 0.85 and 1.07 in all but one instance, although the range of haemoglobin varied from $26 \%$ to $96 \%$ (3.85 to 14.2 g. per $100 \mathrm{ml}$.). The exception showed a colour index of 0.81 .

3. The haemoglobin level is quantitatively related to the blood urea, falling as the blood urea rises in such a manner that each $50 \mathrm{mg}$. rise of urea per $100 \mathrm{ml}$. blood is accompanied by a fall of about $2 \mathrm{~g}$. per $100 \mathrm{ml}$. in haemoglobin (Roscoe, 1952).

4. The quantitative relationship is disturbed in cases where the blood urea is rising very rapidly, changes in haemoglobin lagging behind those of blood urea, but with this exception-the haemoglobin does not depend upon the duration of the uraemia, for patients whose blood urea remains at a fairly constant high level for months (or in rare cases for years) do not show a progressive fall in haemoglobin.

5. The same type of anaemia may occur in extrarenal uraemia of long duration (e.g., pyloric stenosis), and $I$ have seen it occur in uraemia from a spinal injury with urinary retention and overflow incontinence. Severe anaemia also occurs in nephrectomized dogs kept alive by peritoneal lavage (Grollman, Turner, and McLean, 1951).

6. The anaemia is not due to haemodilution, since the blood volume is usually normal or low in these cases (Harris and Gibson, 1939).

7. It is not due to haemorrhages, as even haematuria is nearly always absent in chronic cases of renal failure. A haemorrhagic stage of uraemia may occur terminally, with epistaxis and bleeding gums, but the anaemia is well established long before this stage is reached.

8. There is usually no clear evidence of increased blood destruc tion. Most cases show no increase of serum bilirubin and no increased excretion of urobilinogen (Loge, Lange, and Moore, 1950). Investigation of the survival of transfused cells by the Ashby technique showed a normal survival in one case observed by Dr. M. D. Milne in my department, but Emerson and Burrow 
(1949) claim to have shown an increased rate of destruction of transfused cells. Loge, Lange, and Moore (1950) summarize their investigations by saying that red-cell survival is diminished only in severe cases with gross azotaemia. In these terminal cases reticulocytosis may be found, as we have also observed.

9. Most observers state that the mechanism of the anaemia is depressed bone-marrow function, but according to Callen and Limarzi (1950) the marrow, which is always normoblastic, may bo hypercellular - the defect, they believe, being one of delivery rather than of maturation.

10. The anaemia responds neither to iron nor to liver extract. Utilization of radioactive iron administered intravenously is decreased. Serum iron and erythrocyte protoporphyrin show no characteristic pattern, unlike the anaemia of chronic sepsis (Loge, Lange, and Moore, 1950).

The main conclusion we may draw from these facts is that in chronic renal failure an anaemia regularly develops which varies in severity with the degree of azotaemia, and is due to depression of bone-marrow function or nondelivery of red cells from marrow to peripheral blood. Stanbury (personal communication), however, points out that while the survival rate of transfused cells may be normal, the rate of destruction of the patient's own cells has not been investigated. A slowly developing anaemia due to increased blood destruction might not show a measurable degree of hyperbilirubinaemia, especially if hepatic function is normal.

The fact that there exists a correlation between the severity of the anaemia and the degree of urea retention does not of course mean that the high blood urea is directly responsible for affecting the marrow, but it does suggest, perhaps, that some retained metabolic product is concerned. If so, three obvious possibilities are urea, creatinine, and phosphate. A high plasma phosphate might interfere with iron absorption from the intestine or with iron transport, but in such a case one would expect the anaemia to be hypochromic. Moreover, a high serum phosphate occurs in hypoparathyroidism, and is not associated with anaemia (Milne, personal communication; Drake, Albright, Bauer, and Castleman, 1939 ; Albright and Ellsworth, 1929 ; Albright, Burnett, Smith, and Parson, 1942).

To see if urea would depress the haemoglobin level I took from 30 to $45 \mathrm{~g}$. of urea daily for 16 days, during which time my blood urea was between 50 and $54 \mathrm{mg}$. per $100 \mathrm{ml}$. on waking, and 70 and $90 \mathrm{mg}$. during most of the day. This had no effect whatever upon the haemoglobin, and the experiment was given up because it was only with difficulty compatible with a day's work, the high blood urea producing a dry mouth, thirst, lethargy, and a tendency to headache. Incidentally it had no noticeable effect on weight and appetite, on blood pressure, or on serum sodium concentration or creatinine clearance. By calculation 16 days with a blood urea in this range would be the minimum that might possibly be expected to show some alteration in serial haemoglobin levels estimated by the alkaline haematin method, and although the experiment was negative it was not pursued long enough to disprove finally a connexion betwen urea and haemoglobin.

I next tried creatinine in doses of 3 to $4 \mathrm{~g}$. per day for 29 days, sufficient to produce a serum creatinine of $1.8 \mathrm{mg}$. per $100 \mathrm{ml}$. in the morning and nearly $5 \mathrm{mg}$. later in the day. This also had no effect whatever on the haemoglobin level.

So far, then, we have failed to find the substance responsible for depression of haemoglobin in renal anaemia.

There is, however, another approach to the problem. Most authors consider that the anaemia of renal failure is evidence of a state of uraemic poisoning; that it is something undesirable. Yet restoration of haemoglobin towards normal or even up to normal values has never been shown to have any beneficial effect upon renal function in these cases (Emerson and Burrows, 1949), and it may even prove harmful (Salvesen, 1948).

It has occurred to me that the anaemia may itself be a process of adaptation, and this is my justification for discuss- ing it in these lectures. If the renal blood flow is limited in quantity, as it appears to be in renal failure (Earle, Taggart, and Shannon, 1944 ; Corcoran, Taylor, and Page, 1948) it is obviously to the advantage of glomerular filtration that the blood should contain more than its normal quota of plasma. That the renal plasma flow is carefully regulated in the normal kidney is suggested by studies of anaemia (Bradley and Bradley, 1947 ; Paterson, 1951) and of polycythaemia (de Wardener, McSwiney, and Miles, 1951). These show that when the haematocrit level is reduced, as in anaemia, the total renal blood flow is diminished but the plasma flow remains approximately normal. An increased haematocrit level, as in polycythaemia, results in an increase of total blood flow with some reduction in plasma flow. Paterson also showed that in experimental anaemia the plasma filtered at the glomerulus bore a direct relationship to the amount of plasma presented to it. Representing renal blood flow by RBF, plasma flow by RPF, and haematocrit level by $H$, we have an approximate relationship: $\mathrm{RPF} \propto \frac{1}{\mathrm{H}}$ if $\mathrm{RBF}$ is constant ; RPF $\propto$ RBF if $H$ is constant. Whence RPF $\propto \frac{R B F}{H}$, so that if $\mathrm{RBF}$ is reduced as in renal failure, a corresponding reduction in haematocrit level is necessary to keep the plasma flow as high as possible. If this is associated, as in other cases of anaemia, with an increased cardiac output, renal plasma flow will be even more favourably affected by the development of anaemia.

The fact that in chronic non-progressive cases of renal failure the anaemia reaches a certain degree dependent upon the severity of uraemia, and then remains constant, strongly suggests that a mechanism may exist for the establishment of anaemia in order to conserve the renal plasma flow.

As I remarked at the beginning of these lectures, teleological arguments of this type cannot take us beyond the stage of hypothesis, but further evidence might be obtainable by investigating various aspects of renal function, before and after the transfusion of renal failure patients, in more detail than in the studies already made by Salvesen (1948). Obviously such an investigation is both desirable and justifiable, since transfusion is a therapeutic measure often advised in these cases, and although it improves the general well-being of the patient it is important to know whether it acts favourably or otherwise upon his kidneys.

I had thought to have these studies ready for inclusion in these lectures, but suitable cases are not easy to find. Many of our renal failure patients are in the terminal phase of their illness, when renal function often deteriorates rapidly for no obvious reason and when estimations such as the clearance of para-amino-hippurate probably give quite unreliable information on renal plasma flow. Many of the patients, moreover, have severe hypertensive symptoms, which would in my view make transfusion unwise. Stationary or slowly progressive cases of renal failure without hypertension do not present themselves at the convenience of Lumleian lecturers, so the subject must be left for study in a more leisurely manner.

Even if the hypothesis that the anaemia of renal failure is an adaptation ensuring maximum renal plasma flow is acceptable, it must still be mediated by some factor affecting the bone marrow or the red cells themselves. This factor does not appear to be urea, creatinine, or phosphate. It may be some other retained product. Further search for the anaemia-producing factor would seem to be a profitable investigation to pursue, for if it could be found we might by good fortune discover a factor concerned with the physiological regulation of the volume of red cells in the peripheral blood.

\section{Conclusion}

I have tried to show that most if not all the functional disturbances known to occur in human renal failure are precisely those which occur in animal experiment as a result of reduction in the amount of functioning renal 
substance-that is, loss of nephrons. In such experiments the remaining nephrons enlarge and take on a volume of work which in the normal kidney they are never called upon to perform. The same, I believe, occurs in human disease, and our concept of renal failure should not be one of disordered function, but rather one of extremely efficient function by a renal remnant now too small for its task. I have tried to describe some of the ruses and tricks which the remaining renal substance employs to carry on its work so as to maintain excretory function and to preserve as long as possible the composition of the milieu interieur with regard to sodium, potassium, water, and other substances essential to survival.

I have pleasure in acknowledging the great debt I owe to members of my team in Manchester and formerly in Sheffield for their help, discussion, and criticism. I have referred to them previously as my fellow nephrophiles, and the term is not entirely facetious, for I would like my envoy to be a salutation to the kidney itselfviscus elegantissimum, as Jean Oliver, quoting from the older anatomists, has recently called it. For the kidney has contributed much interest to my life and thought for many years ; I would like to express my admiration of its structure and for the quiet and efficient way in which it handles its problems; and although we are still too ignorant to do much to remedy its disorders, these, I feel, are not the fault of the kidney itself, which seems to devise every possible adaptation to overcome the handicaps imposed upon it by disease.

\section{RuThences}

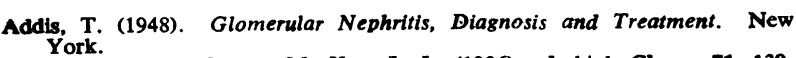

- MacKay, E. M., and MacKay, L. L. (1926). J., biol. Chem., 71, 139. Albright, F., Burnet,, C. H., Smith, P. H., and Parson, W. (1942). Endocrinology, 30, 922.

and Ellsworth, R. (1929). J. clin. Invest., 7, 183

and Reifenstein, E. C. (1948). The Parathyroid Glands and Metobollc Bone Disease. London.

Barter, J. H., and Cotzias, G. C. (1949). J. exp. Med., 89, 643

Berliner, R. W., and Kennedy, T. J. (1948). Proc. Soc. exp. Biol., N.Y., 67, 542 .

Black, D. A. K., Platt, R., and Stanbury, S. W. (1950). Clin. Sct., 9, 205. Bradford, J. R." (1899). J. Physiol., 23, 415.

Bradley, S. E., and Bradley, G. P. (1947). Blood, 2, 192

Brod, J. (1949). Amer. J. Med., 7, 317.

- and Sirota, J. H. (1948). J. clin. Invest., $27,645$.

Brodsky, W. A., and Rapoport, S. (1951). Ibid., 30, 282

Byrom, F. B., and Dodson, L. F. (1948). J. Path. Bact., 60, 357

Callen, I. R., and Limarzi, L. R. (1950). Amer. J. clin. Path., 20, 3.

Chasis, H., and Smith, H. W. (1938). J. clin Invest., 17, 347.

Cancoran, A. C., Taylor, R. D., and Page, I. H. (1948). Ann. intern.

de Wardener, H. E., McSwiney, R. R., and Miles, B. E. (1951). Lancet,

2, 204. Intern. Med., 12, 1751.

Earle, D. P.. Taggart, J. V., and Shannon, J. A. (1944). J. clin. Invest., 23, 119.

Emerson, C. P., and Burrows, B. A. (1949). Ibid., 28, 779.

. Bull. Johns Hopk. HosD., 87, 593.

Frey, E., and Frey, J. (1950). Die Funktionen der gesunden und kranken Niere. Berlin.

Goldblatt, H., Lynch, J., Hanzal, R. F., and Summerville, W, W. (1934). J. exp. Med., 59, 347.

. Hypertenston and Hypertenstive Disease. New York.

Med., 87, 379.

Harris, A. W., and Gibson, J. G. (1939). J. clin. Invest., 18, 527

Hayman. J. M. Shumway, N. P., Dumke, P., and Miller, M. (1939). Ibid., 18, 195.

Hervey, G. R., McCance, R. A., and Tayler, R. G. O. (1946). Nature, Lond., 157,338 .

Boseman, O. (1948). Acta med. scand., Suppl, 216a.

Keith, N. M., and Burchell, H. B. (1949). Amer. J. med. Sct., 217, 1.

Lauson, H. D. (1951). J. appl. Phystol., 4, 227.

Leaf. A. and Camara, A. A. (1949), J. clin. Invest. 28, 1526

Lewis, T. (1925). The Mechanism and Graphic Registration of the Hear Beat. London.

Loge, J. P., Lange. R. D., and Moore, C. V. (1950). J. clin. Invest. 29, 830.

McCance, R. A. (1945). J. Physiol., Lond., 104, 196.

and Widdowson, E. M. (1937). Lancet, 2, 247.

MacKay, L. L., MacKay, E. M., and Addis, T. (1931). J. Nutr., 4, 379.

Marshall. E. K. (1930). Amer. J. Physiol., 94, 1.

Milne, M. D. (1951). Clin. Scl., 10, 471.

Möller, E., McIntosh, J. F., and Van Slyke, D. D. (1929). J. clin. Invest., 6, 427.

Oleesky, S., and Stanbury, S. W. (1951). Lancet, 2. 664.
Oliver, J. (1944-5). The Harvey Lectures, 40, 102.

(1950). J. Urol., 63, 373.

Pappenheimer, A. M., and Wilens, S. L. (1935). Amer. J. Path., 11. 73. Paterson, J. C. S. (1951). Amer. J. Physiol., 164, 682.

Platt, R. (1950). Clin. Scl., 9, 367.

- (1951). Lancet, 1, 1239.

and Davson, J. (1950). Quart. J. Med., n.s. 19, 33

Roscoe, M. H., and Smith, F. W. (1952). Clin. Scl. In press. Rapoport, S. Brodsky, W. A., West, C. D., and Mackler, B. (1949a)
Amer. J. Physiol., 156, 433.

West, C. D., and Brodsky, W. A. (1949b). Ibid., 157, 363.

Roscoe, M. H. (1952). Lancet, 1, 444.

Salvesen, H. A. (1948). Acta med. scand., 131, 337

Selye, H., Stone, H., Nielsen, K., and Leblond, C. P. (1945). Canad. med. Ass. J., 52, 571.

Shannon, J. A. (1938). Amer. J. Physiol., 123, 182

Sharpey-Schafer, E. P. (1944). Clin. Sct., 5, 125.

Smith, H. W. (1937). The Physiology of the Kidney. Oxford Univ. Prose. (1951). The Kldney. Oxford Univ. Press, New York

Stanbury, S. W., and Thomson, A. E. (1951). Clin. Sct., 10, 267.

Thorn, G. W., Koepf, G. F., and Clinton, M. (1944). New Engl. J. Med.

231, 76. Verney, E. (1947). Proc. Roy. Soc. B, 135, 25.

olhard, F. (1931). In Handbuch der inneren Medizin, by G. Bergmann and R. Staehelin, vol. 4. Berlin.

Weiss, E., and Chasis, H. (1943). J. Amer. med. Ass., 123, 277

Welsh, C. A., Wellen, I., Taylor, H. C., jun., and Rosenthal, A. (1944).

White, H. L.. Heinbecker, P., and Rolf, D. (1941). Proc. Soc. exp. Btol.,

Wilson, C.., and Byrom, F. B. (1941). Quart. J. Med., n.s. 10, 65.

Wolf, A. M. C. and Waters, L. L. (1940). Yale J. Biol. Med., 12, 705.

\section{SYMPATHECTOMY FOR RAYNAUD'S DISEASE}

\section{RESULTS OF GANGLIONECTOMY AND PRE- GANGLIONIC SECTION COMPARED}

BY

\section{J. B. KINMONTH, M.S., F.R.C.S.}

AND

G. J. HADFIELD, F.R.C.S.

(From the Surgical Professorial Unit, St. Bartholomew's Hospital)

Sympathetic ganglionectomy for Raynaud's disease of the hands produced - good results in most cases, but relapse sometimes followed it (Ross, 1935). Telford (1935) and Smithwick (1936) suggested that relapse might be avoided by carrying out a purely pre-ganglionic section of the sympathetic chain. The two operations have never been adequately compared. The present study was planned so that a direct comparison could be made between a group of patients who had had preganglionic section and another earlier group treated by ganglionectomy and reported upon by Ross in 1935 . The severity of the disease and the results of operation were assessed by the same methods in each series. The results are compared in Table $I$.

The patients who had undergone pre-ganglionic section were followed for one to thirteen years after operation. All had been operated upon by members of the surgical professorial unit at St. Bartholomew's Hospital. They had been examined at intervals since operation and again for the purpose of this review,

TABLE I.-Results of Different 'Operations for Raynaud's Disease Compared

\begin{tabular}{|c|c|c|c|c|}
\hline \multirow{2}{*}{ Operation } & \multirow{2}{*}{$\begin{array}{l}\text { No of } \\
\text { Patients }\end{array}$} & \multicolumn{3}{|c|}{ Results } \\
\hline & & Success* & Improved $t$ & Failure \\
\hline $\begin{array}{l}\text { Ganglionectomy } \\
\text { series) } \\
\text { Pre-ganglionic section } \\
\text { (series to 1951) }\end{array}$ & $\begin{array}{l}41 \\
39\end{array}$ & $\begin{array}{l}29(71 \%) \\
27(69 \%)\end{array}$ & $\begin{array}{l}4(10 \%) \\
5(13 \%)\end{array}$ & $\begin{array}{l}8(19 \%) \\
7(18 \%)\end{array}$ \\
\hline
\end{tabular}

Attacks less frequent and less severe. No recurrence of ulceration

t Ulcers recurred, but pain less and working capacity increased. 